\title{
Workpiece Machining Accuracy Prediction Based on Milling Simulation
}

\author{
Lv Yan-peng, Wang Ai-min, Wang Xiao-Long \\ School of Mechanical Engineering, Beijing Institute of Technology, Beijing 100081, China
}

\begin{abstract}
To ensure the machining accuracy of workpiece, it is necessary to predict the workpiece deformation in machining process through establishing a high precision workpiece deformation forecast model. To solve these problems, a more efficient variable stiffness analysis model is proposed, which can obtain quantitative stiffness value of the machining surface. Applying simulated cutting force in sampling points using finite element analysis software ABAQUS, the single direction variable stiffness rule can be obtained. First of all, finite element simulation model of face milling is established with the Johnson-Cook material model and failure model of 7050 aluminum alloy. Prediction model is established based on SVM and input data is provided by the finite element software ABAQUS simulation. Results show that the model prediction relative error is less than $5 \%$. It is concluded that the effects of milling parameters on workpiece machining deformation and practical guide for production.
\end{abstract}

\section{Introduction}

7050 aluminum alloy is mainly used in the aerospace field because it has some advantages such as light weight, high strength, high temperature resistance, corrosion resistance. But this component has poor rigidity and is prone to deformation in the processing. It is necessary going through correcting and aging treatment after processing to ensure the machining accuracy of workpiece. Thus how to reduce the workpiece machining deformation is a realistic problem which needs to be settled.

If the workpiece deformation can be predicted accurately before the processing according to the machining parameters to, the machining precision of workpiece can be improved. To achieve this goal, it is necessary to establish a high precision and strong generalization ability machining deformation prediction model which can provide feasible guidance to improve the efficiency of the practical production.

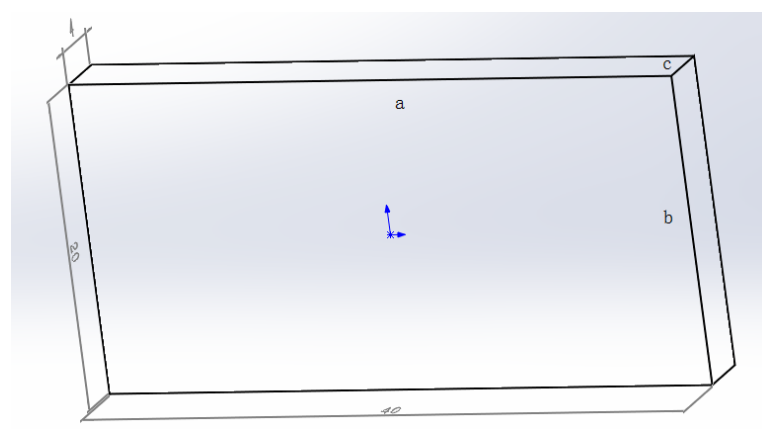

Figure 1. Workpiece structure

\section{Workpiece structure and the clamping form}

The workpiece structure is a cuboid as shown in Fig. 1. Its material is 7050 aluminum alloy. In Fig. 1, a is equal to $40 \mathrm{~mm}, \mathrm{~b}$ is equal to $20 \mathrm{~mm}$, c is equal to $4 \mathrm{~mm}$.

Workpiece is manufactured while the surface of edge $\mathrm{b}, \mathrm{c}$ is fixed.

\section{The simulation theory}

Previous processing deformation prediction model was set up mainly by regression analysis method [1], the neural network [2], etc. The former method in modeling accuracy and generalization ability can't meet the requirements of machining deformation prediction, the latter method need establish a model, which cost a long training time into the local extreme value point and weak generalization ability.

\subsection{SVM}

SVM [3], [4] (Support Vector Machine) was first proposed by Cortes and Vapnik in 1995, which is good at solving the small sample, nonlinear and high dimensional pattern recognition. It overcomes the defect of the neural network in structure, easy to fall into local extremum problems, and combining the advantages of neural network and grey model, and can be applied to the function fitting other Machine learning problems.

The main ideas of the SVM can be summarized as two points: (1) it is to solve the problem of linear 
separable analysis through the use of nonlinear mapping algorithm, which will undivided linear sample lowdimensional input space into a high-dimensional feature space linear separable, so as to make the high dimensional feature space by using linear algorithm for linear analysis on the nonlinear characteristics of samples is possible. (2) it is based on structural risk minimization theory to construct the optimal hyperplane segmentation in the feature space and a certain upper bound in the sample space for the expected risk to a probability.

SVM method ingeniously solved the Curse of Dmensionality. Due to the kernel function expansion theorem, there is no need to know the explicit expression of nonlinear mapping. Because it is establishing linear machine learning in the high dimensional feature space, so compared with the linear model, not only almost does not increase the computational complexity, and to some extent to avoid the "Curse of Dmensionality". All this can be attributed to expand and calculation theory of kernel function.

This paper uses Polynomial Kernel as follow:

$$
K(x, y)=[(x \cdot y)+1]^{d}
$$

\subsection{Johnson-cook constitutive model}

Considering that the cutting parameters are the main factors of the machining deformation, I choose Johnsoncook constitutive model with the support of the theory of thermal coupling force. This model fully consides the friction between cutter and workpiece and elastic-plastic deformation to produce heat of cutting tool and the workpiece, the heat transfer between the workpiece and environmental factors. It is important that the effects of each variable be properly assessed, rather than assuming all distinguishing characteristics are due to strain rate alone.

Johnson-cook model [5]-[7] is a materials expression, which can reflect the strain rate effect and temperature softening effects of ideal elastic-plastic model. It is valid for the temperature range from room temperature to the melting point temperature range, particularly suitable for simulation under high strain rate of metal material. Its specific expression [3] is as follow:

$$
\sigma=\left[A+B \varepsilon^{n}\right] \cdot\left[1+C \ln \left(\frac{\dot{\varepsilon}}{\dot{\varepsilon}_{0}}\right)\right] \cdot\left[1-\left(\frac{t-t_{r}}{t_{m}-t_{r}}\right)^{m}\right]
$$

where $\mathrm{A}, \mathrm{B}, \mathrm{C}, \mathrm{n}$ and $\mathrm{m}$ is outstanding parameter, which can be get by experiment, They respectively are yield stress, Strain hardening constant, strain rate hardening constant strengthening coefficient, stress hardening coefficient and thermal softening coefficient; $\varepsilon, \dot{\varepsilon} 、 \dot{\varepsilon}_{0}$ respectively are equivalent plastic strain, equivalent plastic strain rate, quasi static strain rate; $t 、 t_{r} 、 t_{m}$ respectively are material deformation temperature, environment temperature and melting point.

\subsection{Cutting force model}

Through the consult the manual of metal cutting, we can know the experience formula of the milling force formula as follows :

$$
F_{C}=\frac{C_{F} a_{p}^{x_{F}} a_{f}^{y_{F}} a_{w}^{u_{F}}}{d_{0}^{q_{F}} n^{w_{F}}} k_{F_{C}}
$$

where $a_{p}$ is Back cutting depth, $a_{f}$ is feed engagement, $a_{w}$ is nominal width of cut, $d_{0}$ is milling cutter diameter, $n$ is milling speed. The rest of the parameters can be found through the reference books. Combined with the actual data processing technology, we can calculate the size of cutting force.

In this paper, processing tool is face milling cutter of cemented carbide.

In expression (1), $n=2000 \mathrm{r} / \mathrm{min}, d_{0}=60 \mathrm{~mm}, a_{f}=$ $0.6 \mathrm{~mm} / \mathrm{r}, a_{p}=2 \mathrm{~mm}, a_{w}=53 \mathrm{~mm}, C_{F}=7750, x_{F}=1.0$, $y_{F}=0.75, u_{F}=1.1, w_{F}=0.2, q_{F}=1.3, k_{F C}=0.55$, we get expression (4) after taking these parameters in expression (3), as follow:

$$
F_{C}=\frac{7750 \times 2^{1} \times 0.216^{0.75} \times 53^{1.1}}{60^{1.3} \times 2000^{0.2}} \times 0.55=227.2 \mathrm{~N}
$$

\section{Milling Simulation}

The simulation is based on Johnson-Cook constitutive model as expression (1). In this paper, $\mathrm{A}=400 \mathrm{MPa}, \mathrm{B}=$ $424 \mathrm{MPa}, \mathrm{n}=1.426, \mathrm{C}=0.001, \mathrm{tr}=293 \mathrm{~K}, \mathrm{tm}=863 \mathrm{~K}$.

Milling process simulation flow chart is shown in Fig. 2.

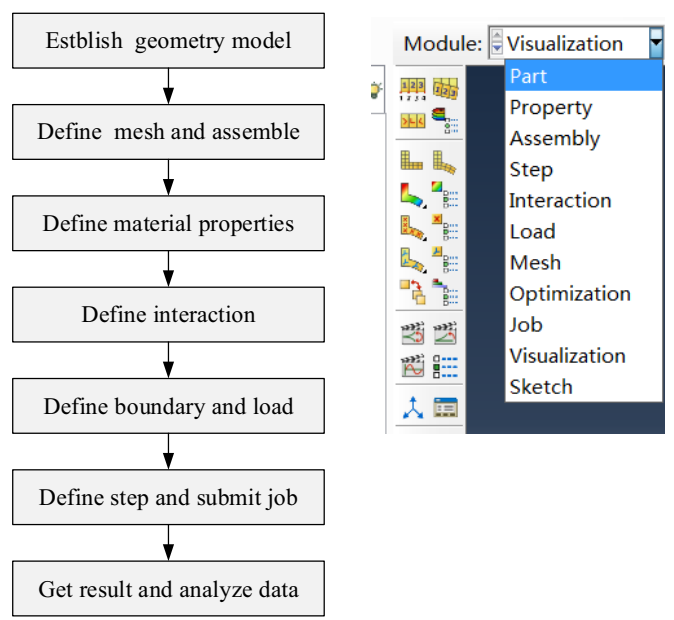

Figure 2. Milling simulation flow chart

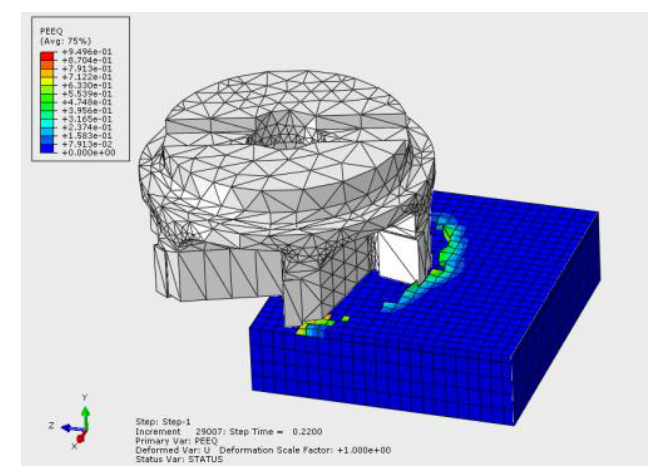

Figure 3. Milling simulation 
Milling process simulation is shown in Fig. 3. The forces of three sides can be obtained the through milling simulation, as shown in the figure below.

Through the simulation of metal milling, we can know curve of the milling force as Fig. 4.

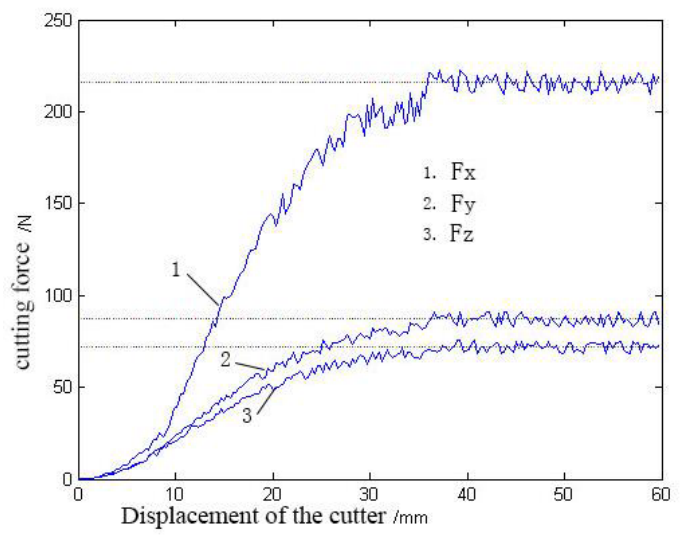

Figure 4. Cutting force curve of milling simulation

The milling force $\mathrm{F}$ can be get according to the results of the simulation as follow:

$$
F=\sqrt{F_{x}^{2}+F_{y}^{2}+F_{z}^{2}}=\sqrt{216^{2}+(-72)^{2}+(-87)^{2}}=243.7 \mathrm{~N}
$$

The milling force error $\varepsilon$ of the simulation calculation and the empirical formula is as follow:

$$
\varepsilon=\frac{\left|F_{C}-F\right|}{F_{C}} \times 100 \%=7.27 \%
$$

The simulation results is close to empirical formula calculation results. Thus we can think the results of the simulation model is accurate.

\section{The experimental process}

This paper in milling process, we try three main process parameters for different values through comparing the rail deformation and stress in order to get optimized process parameters.

\subsection{The situation of the different feeding}

Milling cutter with cutting deep $0.1 \mathrm{~mm}$, the speed of $1000 \mathrm{r} / \mathrm{min}$, the cutter feeding respectively is $1.2 \mathrm{~mm} / \mathrm{r}$, $1.8 \mathrm{~mm}$ and $3.0 \mathrm{~mm} / \mathrm{r}$. Contrast the guide maximum stress and deformation results are as follows:

Table 1. The stress and deformation of workpiece in different feeding

\begin{tabular}{|l|l|l|l|l|l|}
\hline $\begin{array}{l}\text { cutting } \\
\text { deep }\end{array}$ & speed & $\begin{array}{l}\text { cutter } \\
\text { feeding }\end{array}$ & $\begin{array}{l}\text { Max } \\
\text { stress } \\
\mathrm{mm}\end{array}$ & $\begin{array}{l}\text { Max } \\
\text { defor- } \\
\text { mation } \\
\mu \mathrm{min}\end{array}$ & $\begin{array}{l}\text { average } \\
\text { deformat- } \\
\text { ion } \\
\mu \mathrm{m}\end{array}$ \\
\hline 0.1 & 1000 & 1.2 & 105.1 & 62.5 & 34.9 \\
\hline 0.1 & 1000 & 1.8 & 97.4 & 55.1 & 31.2 \\
\hline 0.1 & 1000 & 2.4 & 92.0 & 50.8 & 28.1 \\
\hline
\end{tabular}

\subsection{The situation of the different speed}

Milling cutter with single cutting deep $0.1 \mathrm{~mm}$, feeding is $1.2 \mathrm{~mm} / \mathrm{r}$, the mill speed of $1000 \mathrm{r} / \mathrm{min}$, respectively 1500 $\mathrm{r} / \mathrm{min}$ and $5000 \mathrm{r} / \mathrm{min}$. Contrast the guide maximum stress and deformation results are as follows:

Table 2. The stress and deformation of workpiece in different

\begin{tabular}{|c|c|c|c|c|c|}
\hline $\begin{array}{l}\text { cutting } \\
\text { deep } \\
\text { mm }\end{array}$ & $\mathrm{r} / \mathrm{min}$ & $\begin{array}{l}\text { cutter } \\
\text { feeding } \\
\mathrm{mm} / \mathrm{r}\end{array}$ & $\begin{array}{l}\text { Max } \\
\text { stress } \\
\mathrm{MPa}\end{array}$ & $\begin{array}{l}\text { Max } \\
\text { defor- } \\
\text { mation } \\
\mu \mathrm{m}\end{array}$ & $\begin{array}{l}\text { average } \\
\text { deform- } \\
\text { ation } \\
\mu \mathrm{m}\end{array}$ \\
\hline 0.1 & 1000 & 1.2 & 105.1 & 62.5 & 34.9 \\
\hline 0.1 & 1500 & 1.2 & 101.1 & 59.4 & 30.7 \\
\hline 0.1 & 2000 & 1.2 & 81.4 & 47.2 & 25.3 \\
\hline
\end{tabular}
speed

\subsection{The situation of the different cutting deep}

Milling speed of $2000 \mathrm{r} / \mathrm{min}$, feeding is $1.2 \mathrm{~mm} / \mathrm{r}$, the milling cutter with single cutting depth were taken as $0.05 \mathrm{~mm}, 0.1 \mathrm{~mm}$ and $0.05 \mathrm{~mm}$. Contrast the guide maximum stress and deformation results are as follows :

Table 3. The stress and deformation of workpiece in different

\begin{tabular}{|c|c|c|c|c|c|}
\hline $\begin{array}{l}\text { cutting } \\
\text { deep } \\
\mathrm{mm}\end{array}$ & $\mathrm{r} / \mathrm{min}$ & $\begin{array}{l}\text { cutter } \\
\text { feeding } \\
\mathrm{mm} / \mathrm{r}\end{array}$ & $\begin{array}{l}\begin{array}{l}\text { Max } \\
\text { stress }\end{array} \\
\mathrm{MPa}\end{array}$ & $\begin{array}{l}\text { Max } \\
\text { defor- } \\
\text { mation } \\
\mu \mathrm{m}\end{array}$ & $\begin{array}{l}\text { average } \\
\text { deform- } \\
\text { ation } \\
\mu \mathrm{m}\end{array}$ \\
\hline 0.05 & 1000 & 1.2 & 86.4 & 45.6 & 26.8 \\
\hline 0.1 & 1000 & 1.2 & 105.1 & 62.5 & 34.9 \\
\hline 0.15 & 1000 & 1.2 & 108.2 & 72.4 & 38.1 \\
\hline
\end{tabular}
cutting deep

\section{Conclusion}

1) The stress and deformation are positively related to cutting deep and cutter feeding, are negatively related to speed. Therefore, the selection of cutting depth and feed speed need to be careful in case the workpiece deformation is too large.

2) Cutting deep is the biggest factor influenced the stress and deformation. Therefore, we should pay attention to reduce the cutting depth, and appropriately increase the feed rate and cutting speed, so as to guarantee the machining efficiency and reduce the workpiece deformation.

3) $\mathrm{We}$ can predict the workpiece deformation according to this paper. If we add more simulation data, we will get more accurate prediction.

4) We should do some cutting test to verify the correctness of the simulation results the next step.

\section{References}

1. D. R. Leseur. Experimental investigations of material models for Ti-6Al-4V titanium and 2024-T3 aluminum. Tech. Rep. DOT/FAA/AR-00/25. US department of Transportation. Federal Aviation Administration. September, (2000).

2. G. Kay. Failure modeling of titanium $6 \mathrm{Al}-4 \mathrm{~V}$ and aluminum 2024-T3 with the Johnson-Cook material model. Tech. Rep. DOT/FAA/AR-03/57. US 
department of Transportation, Federal Aviation Administration, September, (2003).

3. Caydas U, Ekici S. Support vector machines models for surface roughness prediction in CNC turning of AISI 304austenitic stainless steel [J]. Journal of Intelligent Manufacturing, 23(3):639-650, (2012).

4. Salgado D, Alonso F, Cambero I. In -process surface roughness prediction system using cutting vibrations in turning $[\mathrm{J}]$.International Journal of Advanced Manufacturing Technology, 43(1):43-51, (2009).

5. Yong Yang, Weiwei Zhu, Study on cutting temperature during milling of titanium alloy based on FEM and experiment. The International Journal of
Advanced Manufacturing Technology, 73(9):15111521, (2014).

6. Ratchev S, Liu S, Becker A A. Error compensation strategy in milling flexible thin-wall parts[J]. Journal of Materials Processing Technology, 162(5):673-681, 2005.

7. Wang, Y., Chen, X., Gindy, N., et al. Elastic Deformation of a Fixture and Turbine Blades System based on Finite Element Analysis, The International Journal of Advanced Manufacturing Technology, 36(4):296-304, (2008). 